\title{
Decadal Climate Variability and Predictability Challenges and Opportunities
}

\author{
Christophe Cassou, Yochanan Kushnir, Ed Hawkins, Anna Pirani, Fred Kucharski, \\ In-Sik Kang, and Nico Caltabiano
}

\section{DECADAL PHENOMENA AND THEIR CHARACTERISTICS. The slowdown in the rate} of global surface warming in the early 2000s, and especially its regional characteristics, highlights the importance of decadal climate variability (DCV) as a modulator of long-term warming trends due to everincreasing anthropogenic forcings (Medhaug et al. 2017). This event, which was termed in the scientific and public domain as a "pause" or "hiatus" in global warming (Lewandowsky et al. 2016), was argued by scientists to be associated with long-recognized [see, e.g., IPCC (1996) for an early assessment] multiyear phenomena, and in particular the undulation of the ocean-atmosphere system in the tropical Pacific (Kosaka and Xie 2013; Meehl et al. 2016a). According to several studies, changes in Earth energy balance at the top of the atmosphere partly related to volcanic aerosols from a series of moderate eruptions in the

AFFILIATIONS: CASSOU-CECI, CNRS-Cerfacs, Université de Toulouse, Toulouse, France; KusHNIR-Lamont-Doherty Earth Observatory, Palisades, New York; HawkIns-National Centre for Atmospheric Science, Department of Meteorology, University of Reading, Reading, United Kingdom; PIRANI-Université ParisSaclay, Saint Aubin, France, and The Abdus Salam International Centre for Theoretical Physics, Trieste, Italy; KUCHARSKI-The Abdus Salam International Centre for Theoretical Physics, Trieste, Italy; KANG - Center of Excellence for Climate Change Research, Department of Meteorology, King Abdulaziz University, Jeddah, Saudi Arabia; CALTABIANO-International CLIVAR Global Project Office, Southampton, United Kingdom

CORRESPONDING AUTHOR: Christophe Cassou, cassou@cerfacs.fr

The abstract for this article can be found in this issue, following the table of contents.

DOI:10.1175/BAMS-D-16-0286.I

(C)2018 American Meteorological Society

For information regarding reuse of this content and general copyright information, consult the AMS Copyright Policy. early 2000s also contributed to the recent hiatus $(\mathrm{Hu}-$ ber and Knutti 2014; Santer et al. 2017). Yet, because of uncertainties in observational estimates in both radiative forcing and global temperature measures, it is impossible to stringently attribute the early $2000 \mathrm{~s}$ hiatus to a specific origin (Hedemann et al. 2017); rather, it should be interpreted as a combination of several factors (Medhaug et al. 2017).

Whether in cases of external forcing due to natural (solar and volcanic) or anthropogenic factors, or during internal climate system interactions, the oceans play a central role in DCV because of their thermal and dynamical inertia. Decadal variations of both regional and global-mean surface temperature can be associated with, and often attributed to, changes in ocean heat uptake and heat redistribution (Yan et al. 2016). The study of the ocean's role in climate has traditionally involved the diagnosis of sea surface temperature (SST) variability as the variable reflecting the interaction with the atmosphere. While the major oceanic basins are usually examined separately when identifying the main climate variability phenomena, what stands out is the related nature of the global patterns and some similarities in their temporal evolutions. Specifically, large-scale, long-term SST variability in one ocean basin is associated with variability in other basins. The global view of these patterns reveals a "network of teleconnections," linking neighboring ocean basins, the tropics and extratropics, and the oceans and land regions (Fig. 1). The two most prominent patterns in this respect are associated with the Atlantic multidecadal oscillation (AMO; Figs. 1b,d) and the Pacific decadal oscillation (PDO; Figs. la,c) or its nearly interchangeable companion referred to as interdecadal Pacific oscillation (IPO; Han et al. 2014; Dong and Dai 2015), ${ }^{1}$ although none of these are true "oscillations."

In the rest of the paper, considering the difficulty in distinguishing between PDO and IPO, we preferably use the latter term. 


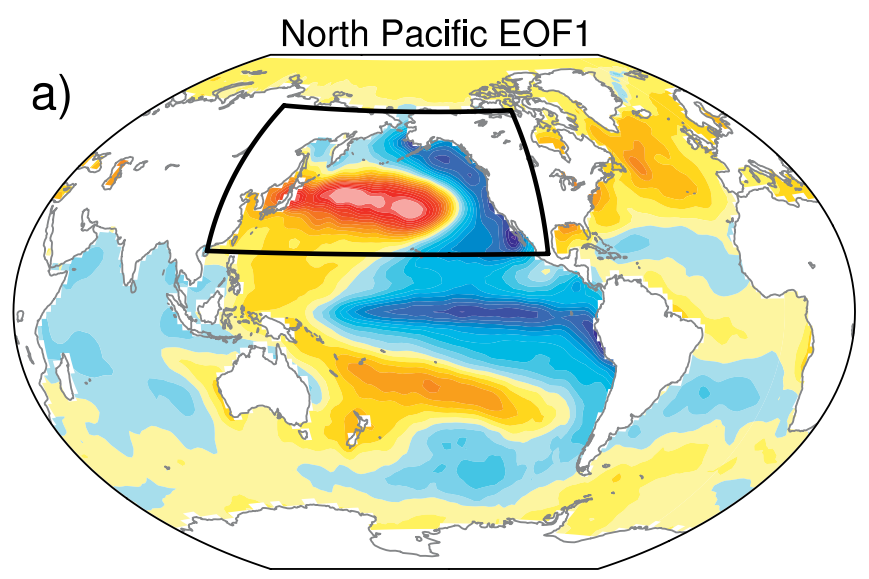

C)
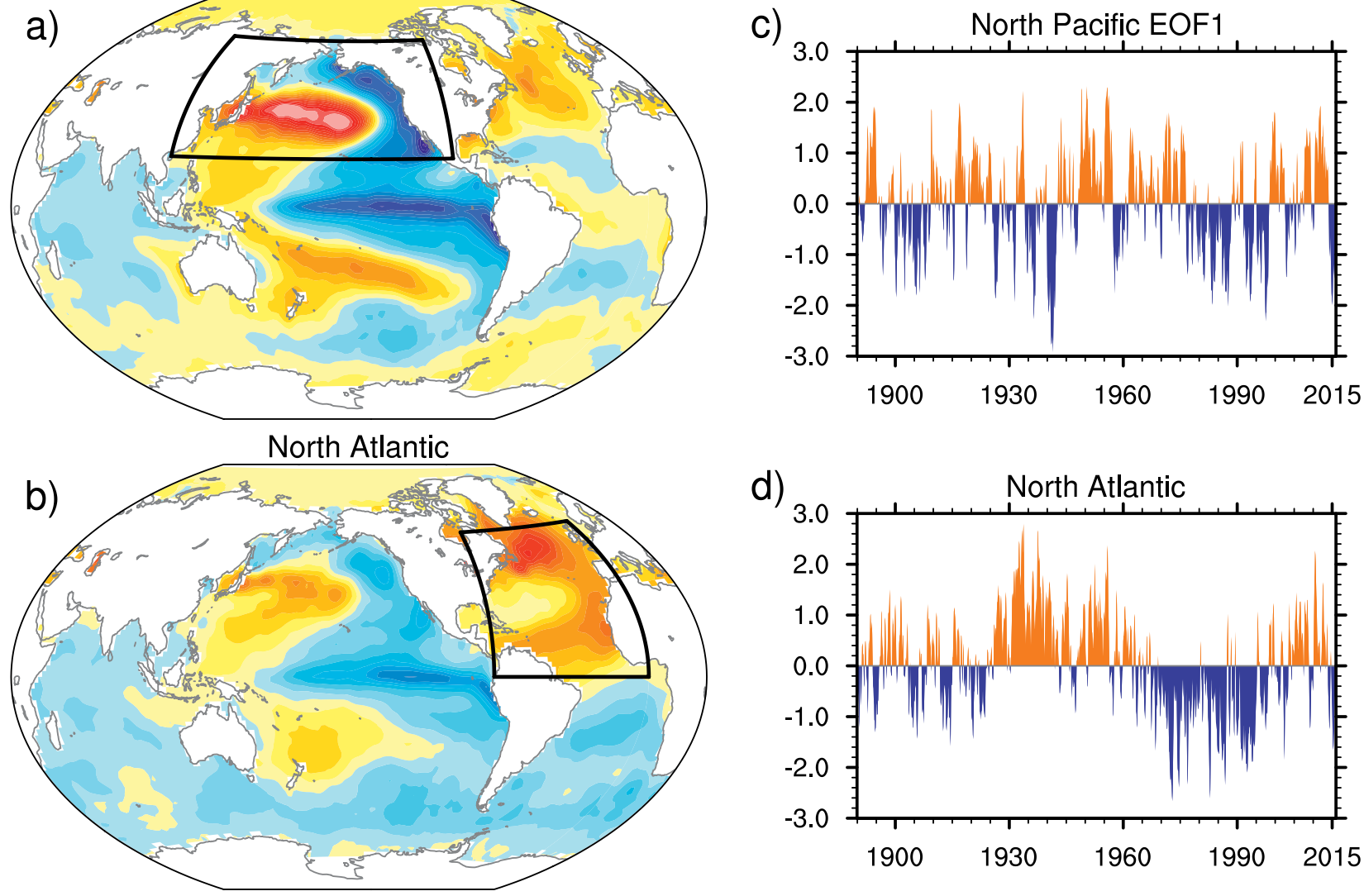

d)

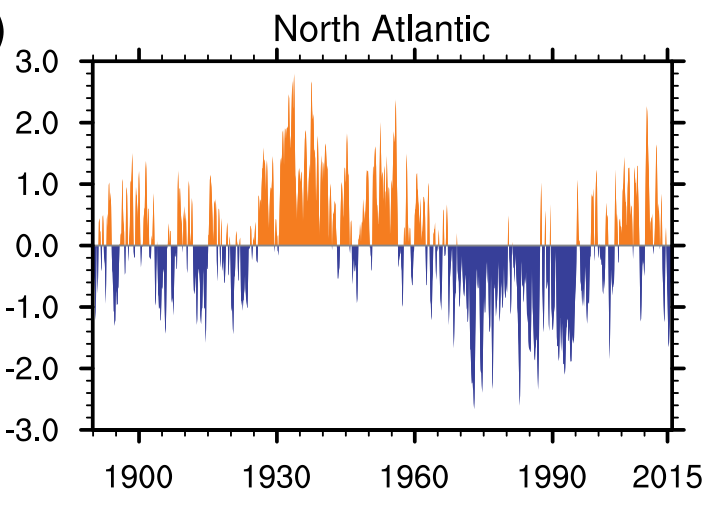

FIG. I. Spatial and temporal characteristics of sea surface temperature anomaly (SSTA) variability in selected ocean basins. (left) Global SSTA $\left({ }^{\circ} \mathrm{C}\right)$ regression maps based on the (a) leading principal component of North Pacific SSTA and (b) North Atlantic SSTA. All indices were standardized prior to computing the regression maps. Index regions are outlined by black boxes. (right) Standardized 3-month running-mean time series of the (c) leading principal component of North Pacific SSTA and (d) North Atlantic SSTA. The global-mean SSTA was removed prior to computing the time series and regression maps. Figure adapted from Deser and Phillips (20I7), CLIVAR exchanges.

The apparent interbasin connectivity seen in DCV SST footprints is likely indicative of the global nature of the associated atmospheric mechanisms that either force or respond to the oceanic variability. However, it is challenging to clearly elucidate the origins of DCV phenomena and especially the underlying oceanic mechanisms because of the short observational records and sparse spatial sampling and because of consistency in terms of instrumental biases. This is even more a limiting factor in the Southern Ocean, where low-frequency variability seems to be present (Fan et al. 2014) but cannot be robustly identified because of data issues. Nonetheless, it is now well recognized that a superposition of multiple processes underlies both the Atlantic and Pacific DCV [see Yeager and Robson (2017) and Newman et al. (2016), respectively].
In the Atlantic, coupled model integrations (e.g., Medhaug and Furevik 2011; Ruprich-Robert and Cassou 2015; references therein), including decadal hindcasts (Robson et al. 2012; Msadek et al. 2014) and forced ocean model simulations (Danabasoglu et al. 2016), demonstrate that the AMO is linked to the variability of the Atlantic meridional overturning circulation (AMOC). Through its associated fluctuations of salt and heat transport and through deep-convection-related mechanisms in the North Atlantic subarctic seas, the AMOC is considered as a driver of the upper-ocean heat content variability and related SST anomalies that project upon the AMO (Buckley and Marshall, 2016). Fingerprints of AMOC variation were found in the subpolar gyre in the form of SST, salinity, and, hence, density anomalies (Häkkinen et al. 2011), particularly in deep-water 
formation regions. Related changes in the state of the ocean are found in the tropical Atlantic, expressed as anticorrelated variations of surface and subsurface ocean temperatures (Zhang et al. 2013), a relationship that is supported by paleoclimate proxy evidence (Parker et al. 2015), although the connection between AMOC variations and tropical Atlantic SSTs remains ambiguous and the mechanism producing tropical Atlantic SST decadal variability remains elusive.

In addition to such ocean dynamical processes, decadal North Atlantic SST evolution since the early twentieth century has also been attributed to external radiative forcing by either anthropogenic [Booth et al. 2012; see Zhang et al. (2013) for further discussion] or natural aerosols. Results combining paleoclimate reconstructions, simulations, and observations have pointed to decadal climatic impacts of volcanic eruptions and to their possible role in the modulation or phase-locking of the AMOC-AMO pattern (Otterå et al. 2010; Swingedouw et al. 2015).

In the Pacific domain, evidence suggests that the PDO should be viewed as the superposition of several phenomena, each governed by different physical processes, each of which is manifested in SST variability in a different part of the basin, rather than being a coherent, single physical mode. Possible physical drivers include the integration of extratropical atmospheric weather noise by the extratropical ocean basins, teleconnections through Rossby wave propagation from the decadal tropical footprint of ENSO, reemergence of persistent subsurface heat content anomalies, and variations in wind stress-driven gyre circulation (Newman et al. 2016). The subtle distinctions between the PDO and IPO may be linked with the multiplicity of governing processes.

According to several studies, the IPO underlies part of the slowdown in the rate of global warming during the early 2000s [see Xie and Kosaka (2017) for a review] and could also be considered as the primary driver of past observed warming slowdowns and accelerations over the historical period (Fyfe et al. 2016; Kosaka and Xie 2016). Model control simulations (with constant external forcing) exhibit IPO-like variability, thus pointing to an internal (i.e., unforced) origin of this phenomenon. However, similar to the AMO, it was suggested that aerosol forcing played a role in determining the temporal phase of the IPO in the late 1990s [Smith et al. 2016; see Kuntz and Schrag (2016) for further discussion]. In any case, determining the cause for the particular IPO event that led to the slowdown in warming in the early 2000s still faces lingering uncertainties (Hedemann et al. 2017).

The climate literature is rich with studies that have linked the AMO and IPO to past observed global climate variations over land. For example, the AMO has been related to the multidecadal fluctuation in Atlantic tropical cyclone activity (Wang et al. 2012) and to the variations of rainfall in the Sahel that led to the devastating droughts and famines of the 1970s and 1980s. Similarly, the multiyear pulses of droughts in the United States and Mexico (e.g., the Dust Bowl in the 1930s and the most recent protracted dry period in California during 2007-16) have been associated with the combined effects of the AMO and IPO (Schubert et al. 2004; Chylek et al. 2014), while the so-called Millennium Drought and warming in Australia has been attributed to a combination of DCV phenomena in the Indo-Pacific and Southern Ocean regions (van Dijk et al. 2013). Controlled experiments in which global climate models are forced to follow AMO and IPO temporal evolution confirm that many of the past observed changes in the climate could be partly attributable to these oceanic anomalies (Zhang and Delworth 2006; Kosaka and Xie 2013; Ruprich-Robert et al. 2017). This motivates the ongoing development of "initialized decadal prediction," in which coupled models are initialized with the observed state of the ocean while anthropogenic and natural forcings are prescribed. Models are integrated for multiple years to try to predict the combined impact of radiative forcing and natural climate variability since the 1960s (e.g., Kirtman et al. 2013).

\section{CHALLENGES AND OUTSTANDING QUESTIONS. In the context of adaptation to} (and mitigation of) the impact of climate change, it is important for a broad range of stakeholders and decision-makers to know how the response to anthropogenic forcing and the impact of natural DCV phenomena will mix together to shape the near-term evolution of climate, especially at regional scales. A major objective of Climate and Ocean: Variability, Predictability and Change (CLIVAR)'s study of DCV and its predictability-the research focus on decadal climate variability and predictability (DCVP) ${ }^{2}$-is to advance the dynamical understanding of the associated phenomena and to improve their representation in models. This is an essential component of the World Climate Research Programme (WCRP) plan

\footnotetext{
${ }^{2}$ www.clivar.org/research-foci/dcvp.
} 
to facilitate a robust and reliable provision of decadal information to society under its "Grand Challenge on Near-Term Climate Prediction." 3 Decadal forecasts were part of phase 5 of the Coupled Model Intercomparison Project (CMIP5; Taylor et al. 2012), and the Decadal Climate Prediction Project (DCPP $)^{4}$ ensures the coordination and design of the modeling experiments in the ongoing CMIP6 (Boer et al. 2016).

In the Atlantic, initialized near-term prediction systems demonstrate substantial skill in hindcasting decadal AMO-like SST anomalies (e.g., van Oldenborgh et al. 2012; Kim et al. 2012; Marotzke et al. 2016), but, noticeably, the added value of the initialization in temperature and precipitation over adjacent land is lost very rapidly (beyond a couple of years), especially over Europe and the American continents (Doblas-Reyes et al. 2013; Meehl et al. 2014a). More robust skill seems to be found when statistical methods to overcome sampling issues are applied (e.g., Robson et al. 2013) or when investigations are focused on case studies (such as the 1960s or 1990s AMO phase transitions). This is perplexing in light of the findings that coupled models with SST restored to the observed anomalies over the Atlantic are able to display part of the ocean's influence on land climate. Part of the loss of predictability over land may be related to systematic errors in the simulation of the spatial structure and temporal properties of the AMO in free coupled models and/or the weak associated teleconnections that communicate ocean signals to the continents (Eade et al. 2014; Qasmi et al. 2017). Skill in a given prediction system might also depend on the model representation of processes or chain of events leading to AMO phenomena. In particular, the AMOC-AMO relationship varies considerably from model to model and leads to a wide range of amplitudes, spatial properties, and preferred time scales of the simulated AMO and associated teleconnections (Ruiz-Barradas et al. 2013; Zhang and Wang 2013; Ba et al. 2014; Peings et al. 2016). Moreover, recent studies also showed that a pattern akin to the AMO SST expression could be identified in a model in which the atmosphere is coupled to a motionless slab-ocean model, calling into question the active role of the ocean dynamics in the phenomenon that could be consequently attributed to random atmospheric forcing [Clement et al. 2015; Cane et al. 2017; see Zhang et al. (2016) and O’Reilly et al. (2016) for further discussion

\footnotetext{
${ }^{3}$ www.wcrp-climate.org/grand-challenges/gc-near-term -climate-prediction.

${ }^{4}$ www.wcrp-climate.org/dcp-overview.
}

of this controversy]. In that context, it is notable that the frequency dependence of the relationship between the AMV and the North Atlantic Oscillation (NAO), which displayed substantial variability on the multidecadal time scale during the twentieth century, seems to be a key aspect for DCV mechanisms (Delworth et al. 2017). Altogether, the role of atmosphere and ocean thermodynamics and dynamics in the surface expression of the AMO and its remote impacts over land remains an active area of research. Resolving the reasons for the very large diversity in model simulations of the AMO is an outstanding challenge, especially the nature and respective weight of the physical mechanisms that contribute to the development of DCV in the Atlantic.

In the Pacific, even if such conclusions are still topics of contention and discussion, initialized coupled models have shown some success in simulating the recent IPO cool phase in the late 1990s (Ding et al. 2013; Meehl et al. 2014b); however, overall performance and results remain inferior to the Atlantic case (Doblas-Reyes et al. 2013). Here too, more research is needed to elucidate the role of the relevant processes and mechanisms that govern the IPO. Fluctuations in tropical Pacific trade winds have been suggested to be a key factor (England et al. 2014), but models fail in reproducing the observed strengthening over the last 30 years (Kociuba and Power 2015). In noninitialized simulations, the basinwide spatial characteristics of the IPO are reasonably well represented (Henley et al. 2017), but the overall ratio of decadal to total variance for SST and oceanic fields is underestimated in most of the models, and errors are pronounced in the extratropics (Farneti, 2016; Nidheesh et al. 2017). Discrepancies could be explained by the (in)ability of the coupled models to effectively simulate all processes generating the IPO (Newman et al. 2016) and/ or by their respective ability to represent the different processes that govern the phenomenon (e.g., a model's ability to simulate oceanic reemergence, Kuroshio dynamics, and stochastic midlatitude atmospheric forcing associated with the variability of the Aleutian low).

For both Atlantic and Pacific DCV, part of the intermodel divergence can be explained by model biases of both the mean state and intrinsic variability. For instance, the formation of Labrador Seawater, which is critical for AMOC variations leading to DCV, is either controlled by salinity or temperature variations as a function of systematic errors in the model's mean state (Menary et al. 2015); this is expected to influence the spatiotemporal characteristics of the simulated AMO. 
For the IPO, the failure in reproducing the pan-Pacific imprint of the decadal mode in some models is related to their intrinsic deficiencies in simulating interannual teleconnections linked to ENSO (Nidheesh et al. 2017).

Yet, evaluating the authenticity of model simulated DCV is challenging due to sparse and short observational records. Based on long control experiments, Qasmi et al. (2017) provides evidence for nonstationarity, in a statistical sense, of the intrinsic spatiotemporal properties of the AMO (variance, persistence, etc.) and associated teleconnections in all CMIP5 models. The identification of the processes that have led to observed DCV since the end of the nineteenth century is further complicated by the presence of external forcing, both natural and anthropogenic. Uncertainties and controversies remain concerning the role of anthropogenic aerosols for both AMO and IPO transitions. This remains an outstanding issue because of the interplay between the response of SST patterns to aerosols and greenhouse gases (GHGs; Xie et al. 2013) and because external forcing can interfere with internal DCV phenomena (Otterå et al. 2010; Tandon and Kushner 2015). In addition, there is no unique and perfect way to remove the impact of external forcing in the observations, and the chosen method may have significant implications for the outcome and hence the interpretations of DCV expression during the historical period (Tandon and Kushner 2015, Lyu and Yu, 2017).

Finally, the presence of drifts and initial shocks in decadal hindcasts is a hindrance for prediction and understanding of recent DCV events. Several driftadjustment procedures, which are mandatory prior to evaluation, exist but are not yet satisfactory in an operational context (Hawkins et al. 2014). Difficulties are mostly related to the temporal nonstationarity of the model drifts due to errors in initial conditions (e.g., Fučkar et al. 2014; Sanchez-Gomez et al. 2016; Pohlmann et al. 2016) and interactions with the model representation and responses to external forcings (Kharin et al. 2012).

Addressing all these challenges and distinguishing the processes contributing to DCV is all the more important since both the latest observations and initialized decadal forecasts suggest that the AMO is undergoing a transition from a warm phase to a cold phase (Hermanson et al. 2014; Robson and Sutton 2016) and that the IPO is trending toward its warm phase (Thoma et al. 2015; Meehl et al. 2016b). Over the Arctic, Yeager et al. (2015) also reported a prediction for a near-term decadal transition, signaling that the rate of decline of sea ice because of GHG forcing is expected to slow down as a result of a weakened AMOC in the 2010s associated with the transition of the AMO to its cool phase. These predictions will be put to test in the next few years (e.g., Smith et al. 2013), and there is urgency to assess their reliability using a process-based evaluation.

\section{FRAMEWORK FOR PROGRESS AND REC-} OMMENDATIONS. All the abovementioned obstacles and challenges test our ability to attribute past variations to the combined role of internal variability and external forcing, as well as predict the near-term future climate evolution on a global and regional scale. Research is needed to deepen our understanding of the physical mechanisms contributing to DCV phenomena, and to make progress, we propose to address DCV issues in terms of the following teleconnections based on the intrinsic nature of the observed SST variability (Fig. 1).

1) Tropical-extratropical teleconnections. Studies are needed to better understand the oceanic basin-scale properties of the DCV patterns and, in particular, the respective origins and roles of their tropical versus extratropical components. Over the Atlantic, a focus is recommended on the processes that facilitate the link between decadal subpolar gyre and tropical Atlantic SST variations-the latter being the primary bridge to global climate variability (Chikamoto et al. 2016; Ruprich-Robert et al. 2017). The interaction and possible feedbacks between the AMOC and AMO variations and the NAO and other atmospheric circulation anomalies, such as blocking events, is a key question in this respect, as these are also very important for driving basinwide Atlantic Ocean variability (Barrier et al. 2014). In addition, uncertainties remain regarding the influence of the external forcing on the North Atlantic modes of variability. The attribution of the late-twentiethcentury observed trend of the NAO to external forcing (Gillett et al. 2003) has been disputed in some recent studies (e.g., Kelley et al. 2012; Cattiaux and Cassou 2013; Deser et al. 2016), and a better evaluation and understanding of the weight of external forcing in the recent decadal changes of the North Atlantic climate is still a research priority. Over the Pacific, it is essential to resolve and understand the exchange of heat between the extratropical and tropical Pacific in governing the IPO as well as the role of midlatitude atmospheric 
stochastic forcings (Drijfhout et al. 2014; Newman et al. 2016).

2) Interbasin teleconnections. Motivated by the temporal quasi synchronization of the main modes of DCV (Fig. 1), research is needed to better characterize and understand the interconnectivity of the different oceanic basins as well as their relationships with the polar regions and to evaluate the robustness and stationarity of these relationships. The role of the AMV in the phase shift of the IPV in the late 1990s (Kucharski et al. 2016) and more broadly in the modulation of ENSO variance (Dong et al. 2006), the role of the IPO-AMO in the cooling of the Southern Ocean and increased sea ice cover over the last 30 years, and the atmospheric bridge between tropical oceanic basins through Walker cell recent reinforcement, among others, are key questions to elevate our understanding of decadal variability and predictability, especially if robust lagged relationships between modes are identified.

3) Ocean-land teleconnections. Motivated by the strong relationship at regional scales between observed oceanic DCV modes and land anomalies, emphasis should be placed on improved understanding of the ocean-land connection at low frequency, especially as CMIP5 models tend to underestimate the overall relationship [see Qasmi et al. (2017) for the AMO] and decadal hindcast skill is critically reduced over the continents. The spatial imprint of the observed hiatus in the early 2000s (strong cooling over North America and Eurasia during wintertime as an important contributor to the slower rise in annual global temperature) as well as recent modeling studies highlight the importance of investigating these issues on a seasonal basis and in terms of changes in the entire probability density function of key parameters such as surface air temperature and precipitation (surmising that the ocean-land connection could occur through changes in the probability of extremes).

4) Vertical teleconnections. Motivated by (i) the importance of the surface-subsurface relationship in the ocean as a key factor for DCV genesis, (ii) the huge discrepancies between oceanic reanalysis products on the three-dimensional thermohaline properties of the water masses (Karspeck et al. 2015), and (iii) the recent evidence for the important role of troposphere-stratosphere coupling in the atmosphere in response to natural decadal forcing (Dunstone et al. 2016), process-oriented approaches and emerging high-resolution model configurations (a stratosphere-resolving atmosphere and refined vertical levels in the ocean component to better simulate vertical processes) should be promoted to tackle this issue. Resolving and understanding the exchange of heat between the upper ocean and the deep ocean in governing the AMO and the IPO is essential for progress.

Across all the four teleconnections, it is essential to assess the respective roles of internal variability and external forcing in DCV at the regional scale (i.e., characterize and understand the observed and simulated spatial responses to external forcing agents and how these forcing agents affect circulation change in the ocean and the atmosphere and related teleconnections) in the presence of internal variability.

Within this "drivers of teleconnectivity" framework, we recommend the following:

1) Use a hierarchy of models and dedicated modeling protocols to study DCV mechanisms and improve their simulations. Both coupled historical simulations and initialized hindcast experiments, together with targeted model sensitivity experiments (e.g., pacemaker or partial coupling configurations), are crucial for mechanistic and process understanding of DCV that is necessary to ultimately advance decadal climate prediction skill and capacities, especially at the regional scale. Empirical approaches to make decadal predictions and utilize observed teleconnections between ocean and land should be also encouraged (Lean and Rind 2009; Suckling et al. 2017).

2) Reduce model biases and drifts. The presence of systematic errors in models has been shown to hamper the spatial representation of DCV patterns and their temporal variability. In forecast mode, drift and shock when models are initialized from observed conditions correspond to a sequence of physical processes by which models adjust toward their own biased equilibria. The determination of the physical origin of model drift and systematic errors should be promoted since such a framework provides clues for the mechanisms underlying DCV in models (Toniazzo and Woolnough 2014; Sanchez-Gomez et al. 2016) and is therefore a promising pathway toward improved simulation and related prediction capability/skill of DCV.

3) Improve the knowledge and observational capacity necessary to track the energy flows through the climate system. This is critical for a better under- 
standing of the relationships/interactions between external climate forcing and internal DCV in affecting past and near-term future changes. Accurate measurement and physical interpretation of threedimensional ocean heat content (heat uptake and heat redistribution) are crucial to make progress in DCV (Trenberth et al. 2016). This should be combined with the precise estimation and analysis of the planetary energy budget at the top of the atmosphere and at the surface (Allan et al. 2014; Smith et al. 2015) from the global scale to the regional scale.

4) Combine the analysis of instrumental observations and models with the information emerging from high-resolution paleoclimate proxy data. Evidence of coherent spatial and temporal patterns of DCV emerge from tree-ring atlases, coral and mollusk records, and other paleoclimatic archives (e.g., Linsley et al. 2015; Tierney et al. 2015; Emile-Geay et al. 2017; Reynolds et al. 2017). These can shed light on the underlying physical processes and provide validation for patterns emerging from the short observational record. Instrumental data rescue efforts should also be expanded to recover the wealth of undigitized records, filling gaps and increasing overlap with the paleoclimatic archives (e.g., the ACRE and OldWeather.org initiatives; Allan et al. 2011).

5) Revisit the traditional definition of DCV phenomena. Care is required when representing and interpreting the climate system with single univariate and basinwide indices, as is too often done in the case of the AMO and IPO indices [see examples in the review by Yeager and Robson (2017)]. It is recommended that the community adopt (i) the use of multivariate metrics ("fingerprints") to identify and discriminate between processes involved, especially when comparing model simulations to observations, and (ii) the notation of decadal variability acronyms (e.g., AMV and IPV) to think in terms of broad spectrum variability instead of temporal oscillations with preferred time scales.

The drivers-of-teleconnectivity theme provides a way to approach the goal of advancing the study of DCV and predictability from different research directions. It goes beyond a preoccupation with changes in the global-mean temperature "popularized" by the hiatus in the early 2000s, a shorthand term for a very complex phenomenon, and directly promotes regional analyses in line with societal needs for local climate information. It fosters an approach to address the intrinsic transdisciplinary issues that challenge progress in DCV and predictability and encourages strengthened links across international community programs such as the CLIVAR DCVP and Consistency between Planetary Energy Balance and Ocean Heat Storage (CONCEPT-Heat) ${ }^{5}$ research foci, Past Global Changes (PAGES2K), ${ }^{6}$ WCRP Global Energy and Water Exchanges (GEWEX), ${ }^{7}$ DCPP, the Model Intercomparison Project on the Climatic Response to Volcanic Forcing (VolMIP), ${ }^{8}$ and the WCRP Grand Challenge on Near-Term Prediction. Because of the difficulties involved in observing and modeling Earth's climate at time scales of a decade or longer, this area of research is wholly dependent on emerging connections between those who perform, collect, and analyze instrumental observations of the present, those who develop and analyze proxies of past climate, and those who develop models and perform dedicated modeling experiments. This drivers-of-teleconnectivity framework was discussed and adopted at the end of the DCVP Research-Focus workshop organized by CLIVAR and the International Centre for Theoretical Physics in Trieste (Italy) in November 2015. ${ }^{9}$

More specifically, the continued PAGES2K effort of collecting, analyzing, and interpreting highresolution climate records, including the development of spatiotemporal reconstructions of climate (temperature and precipitation) variability in both the tropics and the midlatitudes, especially for the last two millennia, should help us to better understand tropical-extratropical and interbasin teleconnections at decadal time scales. Progress on the interpretation of ocean-land connectivity would gain from studying the relationship between land (e.g., tree rings) and ocean proxies (e.g., corals and shells).

On the modeling side, coordinated experiments based on "pacemaker" or partial-coupling modeling

\footnotetext{
${ }^{5}$ www.clivar.org/research-foci/heat-budget.

${ }^{6}$ http://pastglobalchanges.org/ini/wg/2k-network/.

7 www.gewex.org/.

${ }^{8}$ www.volmip.org/index.php.
}

9 The workshop was organized toward meeting the objectives of the CLIVAR Research Focus on DCVP to advance the understanding of the mechanisms and predictability of decadal climate variability. The organizers integrated the plans to establish a new WCRP Grand Challenge on Near-Term Climate Prediction and the development of coordinated modeling strategies to address decadal variability and prediction under CMIP6 led by DCPP. The workshop was attended by around 150 participants and was streamed live to a global audience. 
strategies have been designed to directly address teleconnectivity (DCPP Component C; Boer et al. 2016) and thus perfectly fit within the proposed framework. The emergence of high-resolution models now compatible with DCV studies, together with increasing computing resources, is a promising opportunity for improved model fidelity and better simulation of the four abovementioned teleconnections. Recent work has highlighted (i) the role of mesoscale oceanic fronts in driving the atmosphere and (ii) the role of the stratosphere and storm tracks as transmitters of SST variability toward the continents (Kidston et al. 2015; $\mathrm{Ma}$ et al. 2016). To make progress, increasing computing resources should be also prioritized to promote the production of large ensembles to correctly characterize internal variability; this is essential to accurately attribute observed DCV events, their nature and physical origins, and their interaction with external forcing.

ACKNOWLEDGMENTS. We would like to acknowledge the following organizations for sponsorship and help in enabling and organizing the Trieste Workshop at the origin of this paper: the International CLIVAR Project Office (ICPO), the Past Global Changes (PAGES) project, U.S. CLIVAR, and the National Oceanic and Atmospheric Administration (NOAA). Most sincere thanks go to the Abdus Salam International Centre for Theoretical Physics (ICTP) for their generous support in hosting the workshop and providing an excellent environment for the presentations and discussions. The ICTP organized a hands-on training session on decadal climate variability and predictability. Students were sponsored to attend both the workshop and the training. We are grateful to the organizing committee and to all the members of the CLIVAR DCVP research focus for very fruitful discussions. Access to the workshop program and lectures (slides and videos) are available at http://indico ictp.it/event/al4266/other-view? view=ictptimetable. The authors are very thankful to the four anonymous reviewers who helped considerably improve the original manuscript. CC is supported by CNRS and by the MORDICUS grant under contract ANR-13-SENV-0002-01.

\section{FOR FURTHER READING}

Allan, R., P. Brohan, G. P. Compo, R. Stone, J. Luterbacher, and S. Bronnimann, 2011: The international Atmospheric Circulation Reconstructions over the Earth (ACRE) initiative. Bull. Amer. Meteor. Soc., 92, 14211425, https://doi.org/10.1175/2011BAMS3218.1.

Allan, R. P., C. Liu, N. G. Loeb, M. D. Palmer, M. Roberts, D. Smith, and P.-L. Vidale, 2014: Changes in global net radiative imbalance 1985-2012. Geophys. Res. Lett., 41, 5588-5597, https://doi.org/10.1002/2014GL060962. Ba, J., and Coauthors, 2014: A multi-model comparison of Atlantic multidecadal variability. Climate Dyn., 43, 2333-2348, https://doi.org/10.1007/s00382-014-2056-1.

Barrier, N., C. Cassou, J. Deshayes, and A.-M. Treguier, 2014: Response of North Atlantic Ocean circulation to atmospheric weather regimes. J. Phys. Oceanogr., 44, 179-201, https://doi.org/10.1175/JPO-D-12-0217.1.

Boer, G., and Coauthors, 2016: The Decadal Climate Prediction Project (DCPP) contribution to CMIP6. Geosci. Model Dev., 9, 3751-3777, https://doi.org/10.5194 /gmd-9-3751-2016.

Booth, B. B. B., N. J. Dunstone, P. R. Halloran, T. Andrews, and N. Bellouin, 2012: Aerosols implicated as a prime driver of twentieth-century North Atlantic climate variability. Nature, 484, 228-232, https://doi.org/10.1038 /nature10946.

Buckley, M. W., and J. Marshall, 2016: Observations, inferences, and mechanisms of the Atlantic meridional overturning circulation: A review. Rev. Geophys., 54, 5-63, https://doi.org/10.1002/2015RG000493.

Cane, M. A., A. C. Clement, L. N. Murphy, and K. Bellomo, 2017: Low-pass filtering, heat flux, and Atlantic multidecadal variability. J. Climate, 30, 7529-7553, https:// doi.org/10.1175/JCLI-D-16-0810.1.

Cattiaux, J., and C. Cassou, 2013: Opposite CMIP3/CMIP5 trends in the wintertime northern annular mode explained by combined local sea ice and remote tropical influences. Geophys. Res. Lett., 40, 3682-3687, https:// doi.org/10.1002/grl.50643.

Chikamoto, Y., T. Mochizuki, A. Timmermann, M. Kimoto, and M. Watanabe, 2016: Potential tropical Atlantic impacts on Pacific decadal climate trends. Geophys. Res. Lett., 43, 7143--7151, https://doi .org/10.1002/2016GL069544.

Chylek, P., M. K. Dubey, G. Lesins, J. Li, and N. Hengartner, 2014: Imprint of the Atlantic multi-decadal oscillation and Pacific decadal oscillation on southwestern US climate: Past, present, and future. Climate Dyn., 43, 119-129, https://doi.org/10.1007/s00382-013-1933-3.

Clement, A., K. Bellomo, L. N. Murphy, M. A. Cane, T. Mauritsen, G. Radel, and B. Stevens, 2015: The Atlantic multidecadal oscillation without a role for ocean circulation. Science, 350, 320-324, https://doi.org/10.1126 /science.aab3980.

Danabasoglu, G., and Coauthors, 2016: North Atlantic simulations in Coordinated Ocean-ice Reference Experiments phase II (CORE-II). Part II: inter-annual to decadal variability. Ocean Modell., 97, 65-90, https:// doi.org/10.1016/j.ocemod.2015.11.007. 
Delworth, T. L., F. Zeng, L. Zhang, R. Zhang, G. A. Vecchi, and X. Yang, 2017: The central role of ocean dynamics in connecting the North Atlantic Oscillation to the extratropical component of the Atlantic multidecadal oscillation. J. Climate, 30, 3789-3805, https://doi.org/10.1175 /JCLI-D-16-0358.1.

Deser, C., and A. Phillips, 2017: An overview of decadalscale sea surface temperature variability in the observational record. CLIVAR Exchanges/PAGES Magazine, joint issue, https://doi.org/10.22498/pages.25.1.2.

_ C, C., J. W. Hurrell, and A. S. Phillips, 2016: The role of the North Atlantic Oscillation in European climate projections. Climate Dyn., 49, 3141-3157, https://doi .org/10.1007/s00382-016-3502-z.

Ding, H., R. J. Greatbatch, M. Latif, W. Park, and R. Gerdes, 2013: Hindcast of the $1976 / 77$ and $1998 / 99$ Climate Shifts in the Pacific. J. Climate, 26, 7650-7661, https:// doi.org/10.1175/JCLI-D-12-00626.1.

Doblas-Reyes, F. J., and Coauthors, 2013: Initialized nearterm regional climate change prediction. Nat. Commun., 4, 1715, https://doi.org/10.1038/ncomms2704.

Dong, B., and A. Dai, 2015: The influence of the Interdecadal Pacific Oscillation on temperature and precipitation over the globe. Climate Dyn., 45, 2667-2681, https://doi.org/10.1007/s00382-015-2500-x.

—, R. T. Sutton, and A. A. Scaife, 2006: Multidecadal modulation of El Niño-Southern Oscillation (ENSO) variance by Atlantic Ocean sea surface temperatures. Geophys. Res. Lett., 33, L08705, https://doi .org/10.1029/2006GL025766.

Drijfhout, S. S., A. T. Blaker, S. A. Josey, A. J. G. Nurser, B. Sinha, and M. A. Balmaseda, 2014: Surface warming hiatus caused by increased heat uptake across multiple ocean basins. Geophys. Res. Lett., 41, 7868-7874, https:// doi.org/10.1002/2014GL061456.

Dunstone, N., D. Smith, A. Scaife, L. Hermanson, R. Eade, N. Robinson, M. Andrews, and J. Knight, 2016: Skilful predictions of the winter North Atlantic Oscillation one year ahead. Nat. Geosci., 9, 809-814, https://doi .org/10.1038/ngeo2824.

Eade, R., D. Smith, A. Scaife, E. Wallace, N. Dunstone, L. Hermanson, and N. Robinson, 2014: Do seasonalto-decadal climate predictions under-estimate the predictability of the real world? Geophys. Res. Lett., 41, 5620-5628, https://doi.org/10.1002/2014GL061146.

Emile-Geay, J., and Coauthors, 2017: A global multiproxy database for temperature reconstructions of the Common Era. Scientific Data, https://doi.org/10.1038 /sdata.2017.88.

England, M. H., and Coauthors, 2014: Slowdown of surface greenhouse warming due to recent Pacific trade wind acceleration. Nat. Climate Change, 4, 222-227, https:// doi.org/10.1038/nclimate2106.

Fan, T., C. Deser, and D. P. Schneider, 2014: Recent Antarctic sea ice trends in the context of Southern Ocean surface climate variations since 1950. Geophys. Res. Lett., 41, 2419-2426, https://doi.org/10.1002/2014GL059239.

Farneti, R., 2016: Modelling interdecadal climate variability and the role of the ocean. WIREs Climate Change, $\mathbf{8}$, https://doi.org/10.1002/wcc.441.

Fučkar, N. S., D. Volpi, V. Guemas, and F. J. Doblas-Reyes, 2014: A posteriori adjustment of near-term climate predictions: Accounting for the drift dependence on the initial conditions. Geophys. Res. Lett., 41, 5200-5207, https://doi.org/10.1002/2014GL060815.

Fyfe, J. C., and Coauthors, 2016: Making sense of the early2000s global warming slowdown. Nat. Climate Change, 6, 224-228, https://doi.org/10.1038/nclimate2938.

Gillett, N. P., F. W. Zwiers, A. J. Weaver, and P. A. Stott, 2003: Detection of human influence on sea level pressure. Nature, 422, 292-294, https://doi.org/10.1038 /nature01487.

Häkkinen, S., P. B. Rhines, and D. L. Worthen, 2011: Warm and saline events embedded in the meridional circulation of the northern North Atlantic. J. Geophys. Res., 116, C03006, https://doi .org/10.1029/2010JC006275.

Han, W., and Coauthors, 2014: Intensification of decadal and multi-decadal sea level variability in the western tropical Pacific during recent decades. Climate Dyn., 43, 1357-1379, https://doi.org/10.1007/s00382-013-1951-1.

Hawkins, E., B. Dong, J. Robson, and R. Sutton, 2014: The interpretation and use of biases in decadal climate predictions. J. Climate, 27, 2931-2947, https://doi.org /10.1175/JCLI-D-13-00473.1.

Hedemann, C., T. Mauritsen, J. Jungclaus, and J. Marotzke, 2017: The subtle origins of surface-warming hiatuses. Nat. Climate Change, 7, 336-339, https://doi.org/10.1038 /nclimate3274.

Henley, B. J., and Coauthors, 2017: Spatial and temporal agreement in climate model simulations of the Interdecadal Pacific Oscillation. Environ. Res. Lett., 12, 044011, https://doi.org/10.1088/1748-9326/aa5cc8.

Hermanson, L., R. Eade, N. H. Robinson, N. J. Dunstone, M. B. Andrews, J. R. Knight, A. A. Scaife, and D. Smith, 2014: Forecast cooling of the Atlantic subpolar gyre and associated impacts. Geophys. Res. Lett., 41, 5167--5174, https://doi.org/10.1002/2014GL060420.

Huber, M., and R. Knutti, 2014: Natural variability, radiative forcing and climate response in the recent hiatus reconciled. Nat. Geosci., 7, 651-656, https://doi .org/10.1038/ngeo2228. 
IPCC, 1996: Climate Change 1995: The Science of Climate Change. Cambridge University Press, 572 pp.

Karspeck, A. R., and Coauthors, 2015: Comparison of the Atlantic meridional overturning circulation between 1960 and 2007 in six ocean reanalysis products. Climate Dyn., 49, 957-982, http://doi.org/10.1007 /s00382-015-2787-7.

Kelley, C., M. Ting, R. Seager, and Y. Kushnir, 2012: The relative contributions of radiative forcing and internal climate variability to the late 20th century winter drying of the Mediterranean region. Climate Dyn., 38, 2001-2015, https://doi.org/10.1007/s00382-011-1221-z.

Kharin, V. V., G. J. Boer, W. J. Merryfield, J. F. Scinocca, and W.-S. Lee, 2012: Statistical adjustment of decadal predictions in a changing climate. Geophys. Res. Lett., 39, L19705, https://doi.org/10.1029/2012GL052815.

Kidston, J., A. A. Scaife, S. C. Hardiman, D. M. Mitchell, N. Butchart, M. P. Baldwin, and L. J. Gray, 2015: Stratospheric influence on tropospheric jet streams, storm tracks and surface weather. Nat. Geosci., 8, 433-440, https://doi.org/10.1038/ngeo2424.

Kim, H.-M., P. J. Webster, and J. A. Curry, 2012: Evaluation of short-term climate change prediction in multimodel CMIP5 decadal hindcasts. Geophys. Res. Lett., 39, L10701, https://doi.org/10.1029/2012GL051644.

Kirtman, B., and Coauthors, 2013: Near-term climate change: Projections and predictability. Climate Change 2013: The Physical Science Basis, T. F. Stocker et al., Eds., Cambridge University Press, 953-1028.

Kociuba, G., and S. B. Power, 2015: Inability of CMIP5 models to simulate recent strengthening of the Walker circulation: implications for projections. $J$. Climate, 28, 20-35, https://doi.org/10.1175/JCLI-D-13 -00752.1 .

Kosaka, Y., and S.-P. Xie, 2013: Recent global-warming hiatus tied to equatorial Pacific surface cooling. Nature, 501, 403-407, https://doi.org/10.1038/nature12534.

— , and _ 2016: The tropical Pacific as a key pacemaker of the variable rates of global warming. Nat. Geosci., 9, 669-673, https://doi.org/10.1038/ngeo2770.

Kucharski, F., and Coauthors, 2016: Atlantic forcing of Pacific decadal variability. Climate Dyn., 46, 2337-2351, https://doi.org/10.1007/s00382-015-2705-z.

Kuntz, L. B., and D. P. Schrag, 2016: Impact of Asian aerosol forcing on tropical Pacific circulation, and the relationship to global temperature trends. J. Geophys. Res. Atmos., 121, 403-414, 14403-14413, https://doi .org/10.1002/2016JD025430.

Lean, J. L., and D. H. Rind, 2009: How will Earth's surface temperature change in future decades? Geophys. Res. Lett., 36, L15708, https://doi.org/10.1029/2009GL038932.
Lewandowsky, S., J. S. Risbey, and N. Oreskes, 2016: The "pause" in global warming: Turning a routine fluctuation into a science problem. Bull. Amer. Meteor. Soc., 97, 723-733, https://doi.org/10.1175/BAMS-D-14-00106.1.

Linsley, B. K., H. C. Wu, E. P. Dassié, and D. P. Schrag, 2015: Decadal changes in South Pacific sea surface temperatures and the relationship to the Pacific decadal oscillation and upper ocean heat content. Geophys. Res. Lett., 42, 2358-2366, https://doi.org/10.1002/2015GL063045.

Lyu, K. and J.-Y. Yu, 2017: Climate impacts of the Atlantic multidecadal oscillation simulated in the CMIP5 models: a re-evaluation based on a revised index. Geophys. Res. Lett., 44, 3867-3876, https://doi .org/10.1002/2017GL072681.

Ma, X., and Coauthors, 2016: Western boundary currents regulated by interaction between ocean eddies and the atmosphere. Nature, 535, 533-537, https://doi .org/10.1038/nature18640.

Marotzke, J., and Coauthors, 2016: MiKlip-A National Research Project on Decadal Climate Prediction. Bull. Amer. Meteor. Soc., 97, 2379-2394, https://doi .org/10.1175/BAMS-D-15-00184.1.

Medhaug, I., and T. Furevik, 2011: North Atlantic 20th century multidecadal variability in coupled climate models: Sea surface temperature and ocean overturning circulation. Ocean Sci., 7, 389-404, https://doi .org/10.5194/os-7-389-2011.

-, M. B. Slope, E. M. Fischer, and R. Knutti, 2017: Reconciling controversies about the "global warming hiatus." Nature, 545, 41-47, https://doi.org/10.1038/nature22315.

Meehl, G. A., and Coauthors, 2014a: Decadal climate prediction: An update from the trenches. Bull. Amer. Meteor. Soc., 95, 243-267, https://doi.org/10.1175/BAMS -D-12-00241.1.

_, H. Teng, and J. M. Arblaster, 2014b: Climate model simulations of the observed early-2000s hiatus of global warming. Nat. Climate Change, 4, 898-902, https://doi .org/10.1038/nclimate2357.

— A. Hu, B. D. Santer, and S.-P. Xie, 2016a: Contribution of the Interdecadal Pacific Oscillation to twentieth-century global surface temperature trends. Nat. Climate Chang., 6, 1005-1008, https://doi.org/10.1038 /nclimate3107.

$\_,-$, and H. Teng, 2016b: Initialized decadal prediction for transition to positive phase of the Interdecadal Pacific Oscillation. Nat. Commun., 7, https://doi.org/10.1038 /ncomms11718.

Menary, M. B., D. L. R. Hodson, J. I. Robson, R. T. Sutton, R. A. Wood, and J. A. Hunt, 2015: Exploring the impact of CMIP5 model biases on the simulation of North Atlantic decadal variability. Geophys. Res. 
Lett., 42, 5926-5934, https://doi.org/10.1002/2015 GL064360.

Msadek, R., and Coauthors, 2014: Predicting a decadal shift in North Atlantic climate variability using the GFDL forecast system. J. Climate, 27, 6472-6496, https://doi .org/10.1175/JCLI-D-13-00476.1.

Newman, M., and Coauthors, 2016: The Pacific Decadal Oscillation, revisited. J. Climate, 29, 4399-4427, https:// doi.org/10.1175/JCLI-D-15-0508.1.

Nidheesh, A. G., M. Lengaigne, J. Vialard, T. Izumo, A.S. Unnikrishnan, and C. Cassou, 2017: Influence of ENSO on Pacific Decadal Oscillation in CMIP models and observations. Climate Dyn., 49, 3309-3326, https:/doi .org/10.1007/s00382-016-3514-8.

O'Reilly, C. H., M. Huber, T. Woollings, and L. Zanna, 2016: The signature of low-frequency oceanic forcing in the Atlantic multidecadal oscillation. Geophys. Res. Lett., 43, 2810-2818, https://doi.org/10.1002/2016GL067925.

Otterå, O. H., M. Bentsen, H. Drange, and L. Suo, 2010: External forcing as a metronome for the Atlantic multidecadal variability. Nat. Geosci., 3, 688-694, https:// doi.org/10.1038/ngeo955.

Parker, A. O., M. W. Schmidt, and P. Chang, 2015: Tropical North Atlantic subsurface warming events as a fingerprint for AMOC variability during Marine Isotope Stage 3. Paleoceanogr., 30, 1425-1436, https://doi .org/10.1002/2015PA002832.

Peings, Y., G. Simpkins, and G. Magnusdottir, 2016: Multidecadal fluctuations of the North Atlantic Ocean and feedback on the winter climate in CMIP5 control simulations. J. Geophys. Res. Atmos., 121, 2571-2592, https://doi.org/10.1002/2015JD024107.

Pohlmann, H., J. Kröger, R. J. Greatbatch, and W. Müller, 2016: Initialization shock in decadal hindcasts due to errors in wind stress over the tropical Pacific. Climate Dyn., 49, 2685-2693.

Qasmi, S., C. Cassou and J. Boé, 2017 : Teleconnection between Atlantic Multidecadal Variability and European temperature: Diversity and evaluation of the Coupled Model Intercomparison Project phase 5 models. Geophys. Res. Lett., 44, 11 140-11 149, https://doi .org/10.1002/2017GL074886.

Reynolds, D., C. A. Richardson, J. D. Scourse, P. G. Butler, P. Hollyman, A. Román-Gonzáleza, and I. R. Hall, 2017: Reconstructing North Atlantic marine climate variability using an absolutely-dated sclerochronological network. Palaeogeogr. Palaeoclimatol. Palaeoecol., 465, 333-346, https://doi.org/10.1016/j.palaeo.2016.08.006.

Robson, J., and R. Sutton, 2016: A reversal of climate trends in the North Atlantic since 2005. Nat. Geosci., 9, 513-517, https://doi.org/10.1038/ngeo2727.
,-- K. Lohmann, D. Smith, and M. D. Palmer, 2012: Causes of the rapid warming of the North Atlantic Ocean in the mid-1990s. J. Climate, 25, 4116-4134, https://doi.org/10.1175/JCLI-D-11-00443.1.

,-- , and D. Smith, 2013: Predictable climate impacts of the decadal changes in the ocean in the 1990s. J. Climate, 26, 6329-6339, https://doi.org/10.1175/JCLI -D-12-00827.1.

Ruiz-Barradas, A., S. Nigam, and A. Kavvada, 2013: The Atlantic multidecadal oscillation in twentieth century climate simulations: Uneven progress from CMIP3 to CMIP5. Climate Dyn., 41, 3301-3315, https://doi .org/10.1007/s00382-013-1810-0.

Ruprich-Robert, Y., and C. Cassou, 2015: Combined influences of seasonal East Atlantic Pattern and North Atlantic Oscillation to excite Atlantic multidecadal variability in a climate model. Climate Dyn., 44, 229-253, https://doi.org/10.1007/s00382-014-2176-7.

_ , R. Msadek, F. Castruccio, S. Yeager, T. Delworth, and G. Danabasoglu, 2017: Assessing the climate impacts of the observed Atlantic multidecadal variability using the GFDL CM2.1 and NCAR CESM1 global coupled models. J. Climate, 30, 2785-2810, https://doi.org/10.1175 /JCLI-D-16-0127.1.

Sanchez-Gomez, E., C. Cassou, Y. Ruprich-Robert, E. Fernandez, and L. Terray, 2016: Drifts dynamics in a coupled model initialized for decadal forecasts. Climate Dyn., 46, 1819-1840, https://doi.org/10.1007 /s00382-015-2678-y.

Santer, B. D., and Coauthors, 2017: Causes of differences between model and satellite tropospheric warming rates. Nat. Geosci., 10, 478-485, https://doi.org/10.1038 /ngeo2973.

Schubert, S. D., M. J. Suarez, P. J. Pegion, R. D. Koster, and J. T. Bacmeister, 2004: On the cause of the 1930s dust bowl. Science, 303, 1855-1859, https://doi.org/10.1126 /science.1095048.

Smith, D. M., and Coauthors, 2013: Real-time multimodel decadal climate predictions. Climate Dyn., 41, 2875-2888, https://doi.org/10.1007/s00382-012-1600-0.

_ , and Coauthors, 2015: Earth's energy imbalance since 1960 in observations and CMIP5 models. Geophys. Res. Lett., 42, 1205-1213, https://doi.org/10.1002 /2014GL062669.

— , and Coauthors, 2016: Role of the volcanic and anthropogenic aerosols in the recent global surface warming slowdown. Nat. Climate Change, 6, 936-940, https://doi .org/10.1038/nclimate3058.

Suckling, E., G. J. van Oldenborgh, J. M. Eden, and E. Hawkins, 2017: An empirical model for probabilistic decadal prediction: A global attribution and regional 
hindcasts. Climate Dyn., 48, 3115-3138, https://oi .org/10.1007/s00382-016-3255-8.

Swingedouw, D., P. Ortega, J. Mignot, E. Guilyardi, V. Masson-Delmotte, P. G. Butler, M. Khodri, and R. Séférian, 2015: Bidecadal North Atlantic ocean circulation variability controlled by timing of volcanic eruptions. Nat. Commun., 6, 6545, https://doi.org/10.1038 /ncomms7545.

Tandon, N. F., and P. J. Kushner, 2015: Does external forcing interfere with the AMOC's influence on North Atlantic sea surface temperature? J. Climate, 28, 6309-6323, https://doi.org/10.1175/JCLI-D-14-00664.1.

Taylor, K. E., R. J. Stouffer, and G. A. Meehl, 2012: An Overview of CMIP5 and the Experiment Design. Bull. Amer. Meteor. Soc., 93, 485-498, https://doi.org/10.1175/ BAMS-D-11-00094.1.

Thoma, M., R. J. Greatbatch, C. Kadow, and R. Gerdes, 2015: Decadal hindcasts initialized using observed surface wind stress: evaluation and prediction out to 2024. Geophys. Res. Lett., 42, 6454-6461, https://doi .org/10.1002/2015GL064833.

Tierney, J. E., and Coauthors, 2015: Tropical sea surface temperatures for the past four centuries reconstructed from coral archives. Paleoceanogr., 30, 226-252, https:// doi.org/10.1002/2014PA002717.

Toniazzo, T., and S. Woolnough, 2014: Development of warm SST errors in the southern tropical Atlantic in CMIP5 decadal hindcasts. Climate Dyn., 43, 2889-2913, https://doi.org/10.1007/s00382-013-1691-2.

Trenberth, K. E., J. T. Fasullo, K. von Schuckmann, and L. Cheng, 2016: Insights into Earth's energy imbalance from multiple sources. J. Climate, 29, 7495-7505, https://doi.org/10.1175/JCLI-D-16-0339.1.

van Dijk, A. I. J. M., H. E. Beck, R. S. Crosbie, R. A. M. de Jeu, Y. Y. Liu, G. M. Podger, B. Timbal, and N. R. Viney, 2013: The Millennium Drought in southeast Australia (2001-2009): Natural and human causes and implications for water resources, ecosystems, economy, and society. Water Resour. Res., 49, https://doi.org/10.1002 /wrcr.20123.

van Oldenborgh, G. J., F. J. Doblas-Reyes, B. Wouters, and W. Hazeleger, 2012: Decadal prediction skill in a multimodel ensemble. Climate Dyn., 38, 1263-1280, https:// doi.org/10.1007/s00382-012-1313-4.

Wang, C., S. Dong, A. T. Evan, G. R. Foltz, and S.-K. Lee, 2012: Multidecadal covariability of North Atlantic sea surface temperature, African dust, Sahel rainfall, and Atlantic hurricanes. J. Climate, 25, 5404-5415, https:// doi.org/10.1175/JCLI-D-11-00413.1.

Xie, S.-P., and Y. Kosaka, 2017: What caused the surface warming hiatus from 1998-2013? Curr. Climate Change Rep., 3, 128, https://doi.org/10.1007/s40641-017 -0063-0.

_ B. Bu, and B. Xiang, 2013: Similar spatial patterns of climate responses to aerosol and greenhouse gas changes. Nat. Geosci., 6, 828-832, https://doi.org/10.1038 /ngeo1931.

_-, Y. Kosaka, and Y. Okumura, 2016: Distinct energy budgets for anthropogenic and natural changes during global warming hiatus. Nat. Geosci., 9, 29-33, https:// doi.org/10.1038/ngeo2581.

Yan, X.-H., T. Boyer, K. Trenberth, T. R. Karl, S.-P. Xie, V. Nieves, K.-K. Tung, and D. Roemmich, 2016: The global warming hiatus: Slowdown or redistribution? Earths Future, 4, 472-482, https://doi.org /10.1002/2016EF000417.

Yeager, S. G., and J. J. Robson, 2017: Recent progress in understanding and predicting decadal climate variability. Curr. Clim. Change Rep., 3, 112-127, https://doi .org/10.1007/s40641-017-0064-z.

—, A. R. Karspeck, and G. Danabasoglu, 2015: Predicted slowdown in the rate of Arctic sea ice loss. Geophys. Res. Lett., 42, 10 704-10 713, https://doi.org/10.1002 /2015GL065364.

Zhang, L., and C. Wang, 2013: Multidecadal North Atlantic sea surface temperature and Atlantic meridional overturning circulation variability in CMIP5 historical simulations. J. Geophys. Res. C Oceans, 118, 5772-5791, https://doi.org/10.1002/jgrc.20390.

Zhang, R., and T. L. Delworth, 2006: Impact of Atlantic multidecadal oscillations on India/Sahel rainfall and Atlantic hurricanes. Geophys. Res. Lett., 33, L17712, https://doi.org/10.1029/2006GL026267.

— , and Coauthors, 2013: Have aerosols caused the observed Atlantic multidecadal variability? J. Atmos. Sci., 70, 1135-1144, https://doi.org/10.1175/JAS -D-12-0331.1.

— , and Coauthors, 2016: Comment on "The Atlantic multidecadal oscillation without a role for ocean circulation." Science, 352, 1527, https://doi.org/10.1126 /science.aaf1660. 